of these structures that an explanation of the phenomena can be found. I quite admit that some of Mr. Watts's sections showed that the perlitic shrinkage fissures of the glass-magma did pass into, and through, the quartz-crystals: but it is not to be inferred from this that the quartz-crystals had perlitic structure, as I shall endeavour to show. Let us consider for a moment the process of consolidation from the molten state. It is clear that the silica consolidated before the glass-magma; and in forming distinct crystals it obeyed the law of its molecular constitution, which obliges it to take the form of a hexagonal prism terminated by a pyramid. On the other hand the amorphous (or non-crystalline) magma is governed by an entirely different set of molecular forces and tries to form a series of concentric globules, somewhat as basalt on cooling often forms globular masses with concentric envelopes. The globular is the primary form of a cooling body. It is clear that the molecular constitutions of the quartz-crystal and of the non-crystalline magma are essentially different, and this distinction finds its result in the diverse forms and structures of the two. If this be admitted it will not be difficult to account for the apparent perlitic fissures traversing some of the quartz-crystals, as shown in some of the specimens. Though these have had priority over the magma in consolidation, yet they were necessarily highly heated and somewhat soft owing to the liquid state of the enclosing magma; and this being so, as the perlitic fissures were being developed in the latter they would exert a pull upon the parts of the quartz-crystals in contact, the force developed by contraction in the case of each globule of the magma tending to draw the mass towards its centre. The quartz being (as has been observed) in a somewhat soft condition would be unable to withstand this force, and in such cases it would give way; and fissures would be produced continuous with one or more in the enclosing glassmagma; bnt this does not prove that the quartz itself has a perlitic structure.

Edward Huld.

22nd March, 1894.

ON THE POSSIBLE MARINE ORIGIN OF THE LOESS.

Sir,-One of the difficulties that faced me in my paper on the "Submergence of Western Europe" 1 was the want of evidence to prove distinctly that the land had been under the sea. As, however, all the physical evidence concurred to show that the various forms of the Rubble-drift indicated a transient disturbance, I concluded that the submergence had been of too short a duration to allow of the establishment of a marine fauna in the area submerged. It was therefore with much satisfaction that I found the other day confirmation of a very unexpected character in a paper publisbed in the last number of the "Bulletin de la Société Belge de Geologie." 2 In treating of the Loess I described a portion of it as of fluviatile origin,

1 Phil. Trans. for 1893, p. 903.

2 lid. Mareh 1894, p. 118. 
whilst I considered that the high- and mid-level Juess belonged to the Rubble-drift, and was theretore of marine origin. In the paper I now refer to, by M. Xavier Stainor, he gives the analy ses of some of the Belgian Loess, in which, besides the ordinary ingredients, a notable proportion of Chloride of Sodium, in one case as much as 1.17 per cent., has been found. This Loess contains the usual common land shells-Pupa marginata, Succinea oblonga, and Helix hispida.

ShorehaM, Kent. April 19th.

Joseph Prestwich.

OBITUAEY.

\section{WILLIAM PENGELLY, F.R.S., F.G.S.}

BorN 12Th JANUARY, 1812.

Dikd 17 Th Makch, 1894.

There has just been gathered to his rest, in his 83rd year, one of that sinall band of Geologists who assisted Falconer, Busk, Lyell, Prestwich, Lartet, Christy, Evans, Rupert Jones, Boyd Dawkins, and a fow others, to place upon a scientific basis that inquiry into the evidence of Pre-historic man which was systematically commenced in this country by the exploration of Brixham Cave in 18.58. This work, which was carried out under the auspices of the Royal and Geological Societies by Mr. William Pengelly, of Torquay, yielded most important results, and was followed, in 1864, by a similar investigation of the historic Kent's Cavern, Torquay (originally partially explored by the Rev. J. McEnery in 1825), and, like the Brixham Cave, carried out with untiring zeal by Mr. Pengelly for a period of more than fifteen years (see British Association Reports 1865-1880).

- William Pengelly was born at East Looe in Cornwall, January 12th, 1812. Coming to Torquay as a young man, he opened a school, which he carried on for some years on the Pestalozzian system, and was one of the first to introduce the use of the chalk and black-board in imparting instruction. ${ }^{1}$

The author of numerous treatises on the Devonian and Triassic Rocks of Devonshire, on St. Michael's Mount in Cornwall, and many other geological subjects, Mr. Pengelly, in conjunction with Dr. Heer, of Zurich, published a monograph on "The Lignites of Bovey Tracey," which is regarded as a most valuable scientific work. His assiduity in the collection and arrangement of specimens is testified by the magnificent series of Devonian fossils which, under the title of the Pengelly Collection, was lodged in the Museum of Oxford University by the Baroness Burdett-Coutts in connection with the Burdett-Coutts Scholarship, and also by the splendid collections of bones and flint-implements from Kent's Cavern, which he has placed in the British Museum and in the Museum

1 Amongst his private pupils in Mathematics was Miss (afterwards the Baroness) Burdett-Coutts, who, through life, remained his staunch friend. 